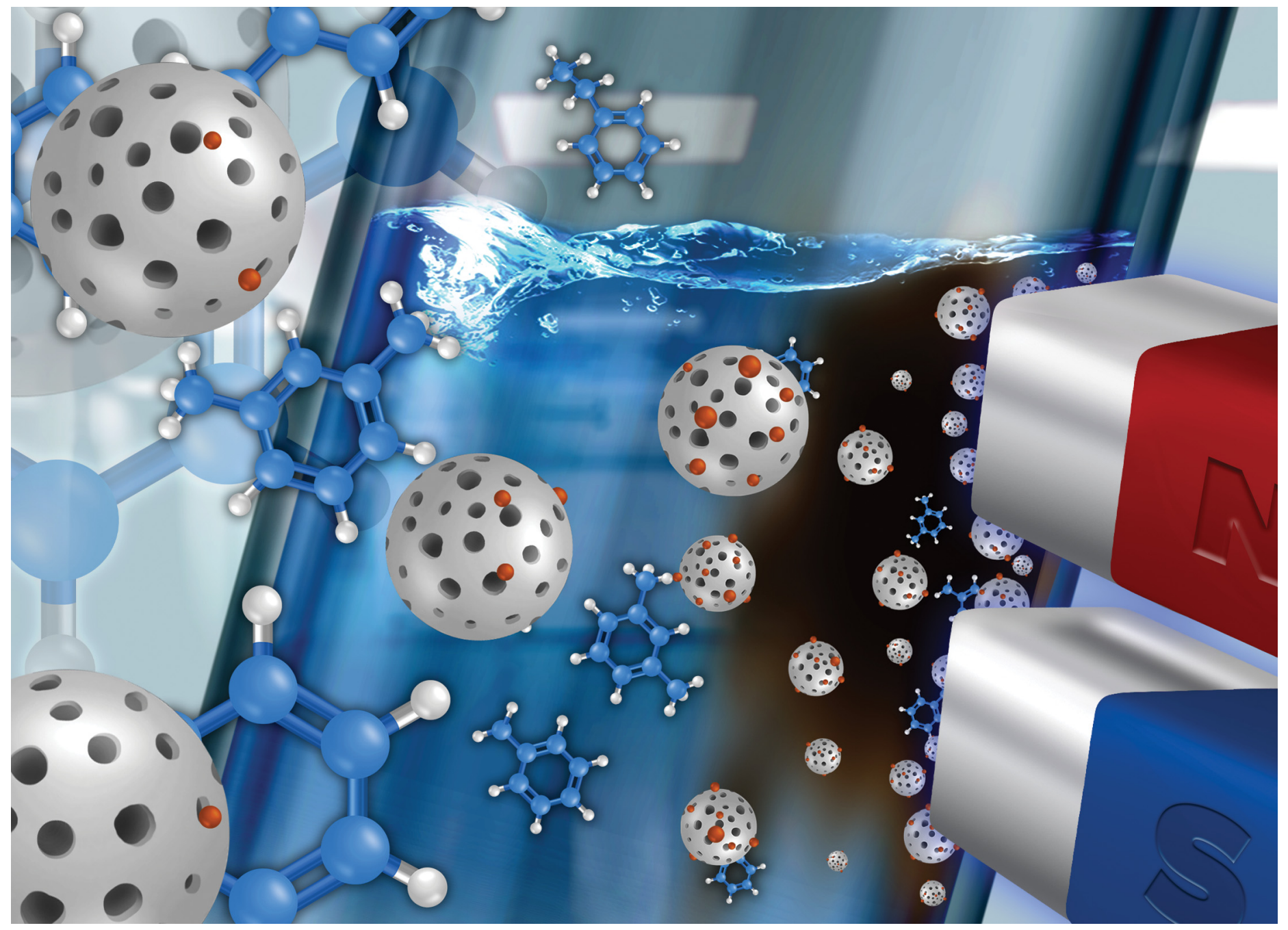

Showcasing research from M Sc. Daniel García and Prof. Koiti Araki's Group at Institute of Chemistry, University of Sao Paulo, Brazil.

SPION-decorated organofunctionalized MCM48 silica-based nanocomposites for magnetic solid-phase extraction

An organo-functionalized magnetic silica-based adsorbent with ordered 3D porous architecture and decorated with SPION for efficient magnetic solid phase extraction of BTEX pollutants in water is showcased, a widely pursued material for faster and efficient pre-concentration of environmental samples.

\section{As featured in:}

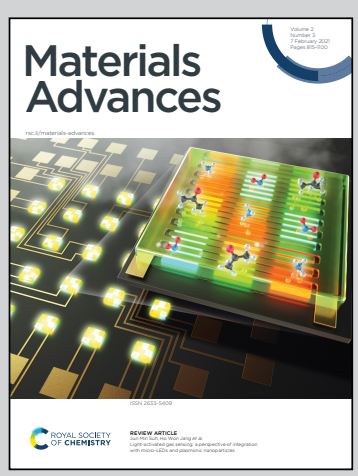

See Koiti Araki et al.,

Mater. Adv., 2021, 2, 963. 
Check for updates

Cite this: Mater. Adv., 2021,

2, 963
Received 16th December 2020, Accepted 19th January 2021

DOI: $10.1039 / \mathrm{d} 0 \mathrm{ma00989j}$

rsc.li/materials-advances

\title{
SPION-decorated organofunctionalized MCM48 silica-based nanocomposites for magnetic solid-phase extraction $\dagger$
}

\author{
Daniel Garcia-Osorio, (D) ${ }^{a}$ Helton P. Nogueira, (D) a Josué M. Gonçalves, (D) ${ }^{a}$ \\ Sergio H. Toma, (D) ${ }^{a}$ Sergio Garcia-Segura ${ }^{b}$ and Koiti Araki (D) *a
}

\begin{abstract}
One of the most commonly used parameters to evaluate the environmental impact of petrochemicalassociated industries and its consequence on human health is the presence of benzene, toluene, ethylbenzene, and xylene in water, which are known as BTEX. The removal of these compounds from groundwater, and thus assuring the quality of this resource, is of high relevance but challenging for regions where the technologically advanced devices required for analytical control are unavailable. Accordingly, herein, a novel silica-based nanocomposite adsorbent (MCM48/SPION/C8) was developed together with an efficient magnetic concentration/extraction and recovery method for BTEX contaminants in water samples, allowing their quantitative extraction and recovery and analysis, even in outdated systems. The implementation of magnetic nanoparticles enabled analysis by magnetic solidphase extraction (mSPE) as expected due to the tailor-made adsorption/desorption properties associated with the easy and fast separation of the adsorbent, its recycling, and reuse. Organofunctionalization of hydrophilic and highly ordered mesoporous silica MCM48 with alkyl chains enabled hydrophobic interactions, thus tailoring its affinity for BTEX species. The novel nanocomposite adsorbent was characterized and compared with a state-of-art commercial product, demonstrating that it outperforms conventional solid-phase extraction materials in terms of recovery efficiency due to its higher specific surface area and entrapment in the hierarchical mesoporous structure achieved upon organofunctionalization with octylsilane.
\end{abstract}

\section{Introduction}

Oil and gas extraction and the petrochemical industry have a considerable water footprint. ${ }^{1-3}$ Indeed, on average, 4 barrels of water are produced per barrel of extracted oil. ${ }^{3}$ However, the anthropogenic release of oil products is more commonly associated with refining processes and accidental spills. The numerous hydrocarbon and aromatic pollutants associated with petroleum include benzene, toluene, ethylbenzene and xylenes. ${ }^{4-7}$ The complex mixture of these volatile organic compounds (VOCs) in water are also known as BTEX. They are slightly miscible with water and are present in very low concentrations (ppm-ppt) in contaminated water samples. $^{8,9}$ Nevertheless, BTEX has known

\footnotetext{
${ }^{a}$ Department of Fundamental Chemistry, Institute of Chemistry, University of Sao Paulo, Av. Prof. Lineu Prestes 748, Sao Paulo, SP, 05508-000, Brazil. E-mail: koiaraki@iq.usp.br

${ }^{b}$ Nanosystems Engineering Research Center for Nanotechnology-Enabled Water Treatment, School of Sustainable Engineering and the Built Environment, Arizona State University, Tempe, AZ 85287-3005, USA

$\dagger$ Electronic supplementary information (ESI) available. See DOI: 10.1039/ d0ma00989j
}

carcinogenicity, even at very low concentrations, and thus is major health and environmental concern. ${ }^{4-6,10,11}$

Thus, several analytical methods have been developed to evaluate the relevant water quality parameter. ${ }^{12-17}$ The major barrier for the accurate quantification of BTEX is their low concentrations (aqueous miscibility: benzene, $1790 \mathrm{mg} \mathrm{L}{ }^{-1}$, toluene, $526 \mathrm{mg} \mathrm{L}^{-1}$, ethylbenzene, $169 \mathrm{mg} \mathrm{L}^{-1}, o$-xylene, $178 \mathrm{mg} \mathrm{L}^{-1}, m$-xylene, $161 \mathrm{mg} \mathrm{L}^{-1}$, and p-xylene, $\left.162 \mathrm{mg} \mathrm{L}^{-1}\right)^{4,5}$ and the presence of several interferents in water bodies. Accordingly, extraction and pre-concentration are the most common procedures used to quantify these aromatic compounds, despite the high volatility of BTEX, which implies additional difficulties. Solid-phase extraction is not considered appropriate for VOCs due to the generally long contact time with air, which results in the volatilization and substantial loss of these analytes. ${ }^{18,19}$ Conversely, liquid-liquid extraction has low reproducibility and requires large quantities of hazardous organic solvents that are also the object of environmental concern. $^{17,20}$

Carbonaceous adsorbents have limited application due to the strong interactions that poison the sorbent surface and diminish the recovery efficiency during the extraction step, ${ }^{21}$ 
whereas zeolites ${ }^{14}$ and silica ${ }^{22}$ have too low affinity and poor selectivity for aromatic compounds such as BTEX. Another class of materials that have been successfully explored in the literature are MOFs ${ }^{23,24}$ however, the processes for their largescale production are not well established, making them expensive.

In this work, we present a promising approach for the use of nanofunctionalized silica-based composite materials. Highly ordered mesoporous silica (MCM48) has an enhanced specific surface area and can be tailored to selectively target some classes of analytes. For example, organofunctionalization with alkyl silanes (C8) can enhance the selectivity towards BTEX by enabling hydrophobic interactions with these low miscibility pollutants. $^{25,26}$ Furthermore, a nanocomposite incorporating superparamagnetic iron-oxide nanoparticles (SPIONs) provides a unique framework for quick magnetic recovery after adsorption, making its recovery/reuse after extraction possible. ${ }^{27,28}$ Accordingly, a new selective adsorbent coupled with an efficient extraction method emerges as an interesting alternative for the concentration/extraction of these contaminants. This idea was realized by combining the organofunctionalization of MCM48 and binding of SPIONs on the grain surface to implement the possibility of magnetic recovery. The performance of the novel MCM48/SPION/C8 material was benchmarked against commercial adsorbents, demonstrating its high adsorption capacity and selective BTEX extraction from real water matrices.

\section{Results and discussion}

\section{Characterization of the nano-enabled adsorbents}

Fig. 1 illustrates the diffractograms of pristine MCM48 and the organofunctionalized MCM48/SPION. The diffractograms at a low angle showed the characteristic pattern of the Ia3d space symmetry group, which is associated with a highly organized mesoporous silica, ${ }^{29}$ consistent with the MCM48 structure. The displacement of the peaks depicted by MCM48/SPION/C8 was attributed to the interpore distance diminution due to particle shrinkage during the thermal treatment conducted in the organofunctionalization process. ${ }^{30-32}$ However, the nanocomposite maintained the highly organized structure and symmetry of MCM48. These patterns were not observed for commercial silica gel $60\left(\mathrm{SiO}_{2}\right)$, which has non-ordered pores.

The XRD analysis at conventional $2 \theta$ values showed the characteristic peak at $23^{\circ}$, corresponding to the $\mathrm{Si}-\mathrm{O}$ ordering pattern. This is usually observed in silica materials, including amorphous structures such as silica gel $60 .{ }^{33}$ It is important to note the display of well-defined diffraction peaks in MCM48/ SPION/C8 associated with the presence of magnetite with the characteristic crystallographic planes of iron spinel corresponding to the (220), (311), (400), (511), and (440) planes, which are consistent with the JCPDS cards of magnetite (PDF 74-0748). ${ }^{34}$ Thus, these results suggest the successful formation of the MCM48/SPION/C8 and $\mathrm{SiO}_{2} / \mathrm{SPION} / \mathrm{C} 8$ nanocomposites. The functionalization process preserved the diffraction pattern but induced a displacement in the small-angle XRD peaks to
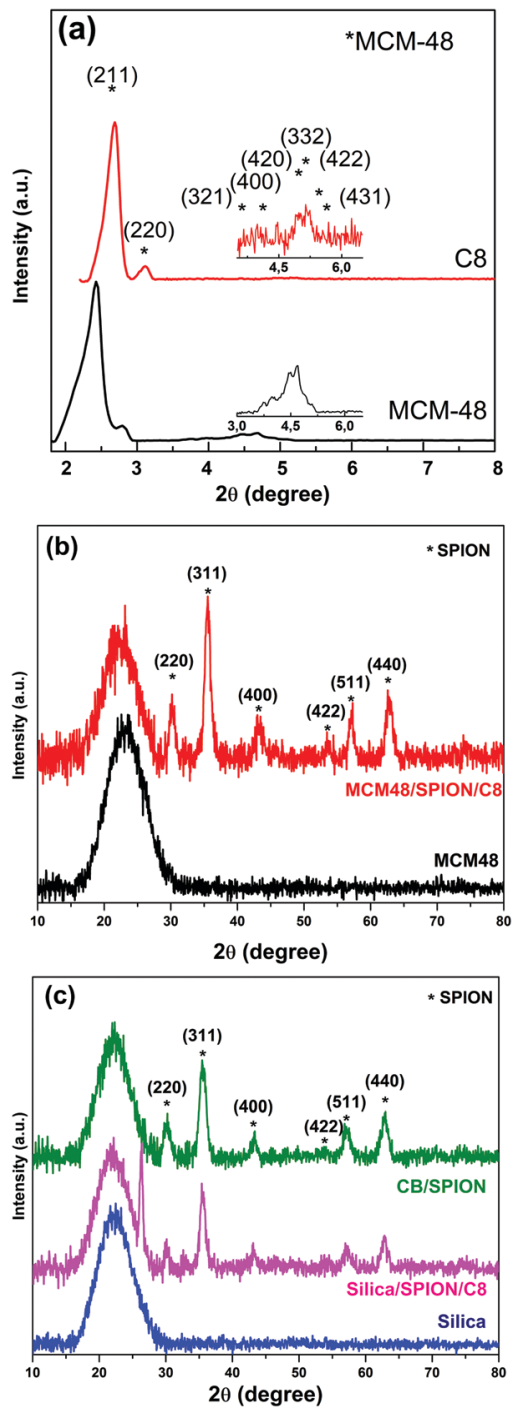

Fig. 1 X-ray diffractograms of pristine MCM-48 (black line) and nanocomposite MCM48/SPION/C8 (red line) at (a) small-angle X-ray scattering and (b) wide-angle X-ray diffraction. (c) Comparison of the XRD patterns of $\mathrm{CB} / \mathrm{SPION}$ (green line), silica gel 60 (blue line) and $\mathrm{SiO}_{2} /$ SPION/C8 (pink line) at wide-angle $\mathrm{X}$-ray diffraction.

larger $2 \theta$ values, as expected for a decrease in interpore distances (shrinkage effect produced by the heat processing involved in the functionalization), as seen in Fig. 2b (BET isotherms). The presence of quartz crystals as a contaminant in the silica-based nanocomposite (silica/SPION/C8) is evidenced by the sharp and high intensity peak at $27^{\circ}(101)$.

The magnetization curves of the nanocomposites measured by vibrating sample magnetometry (VSM) in the range of -20 to 20 kOe are shown in Fig. S1 (ESI $\dagger$ ). The very low magnetic hysteresis (below 50 Oe) and perfectly flat saturation at 5.1-5.3 emu $\mathrm{g}^{-1}$ can be assigned to the superparamagnetic magnetite nanoparticles bound on (decorating) the adsorbent material grains. This magnetization is consistent with the relative amount of SPION (10 wt\%) incorporated in the adsorbents in the preparation process given that the magnetization of SPION is $53 \mathrm{emu}^{-1}$. The correlation between SPION content and magnetic saturation 
(a)

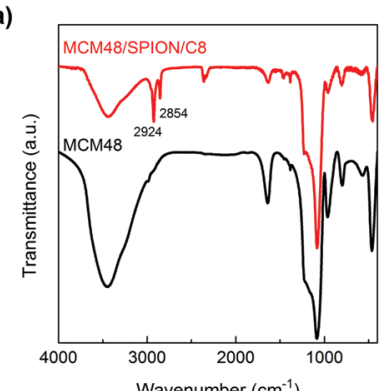

(c) $600-1.2$

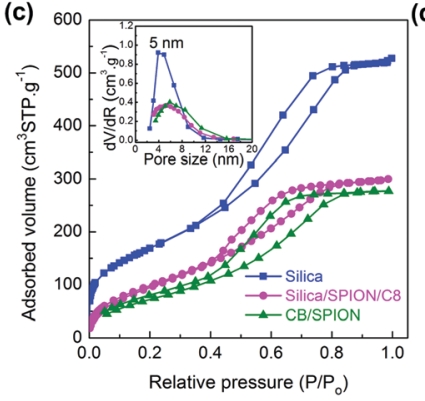

(b)

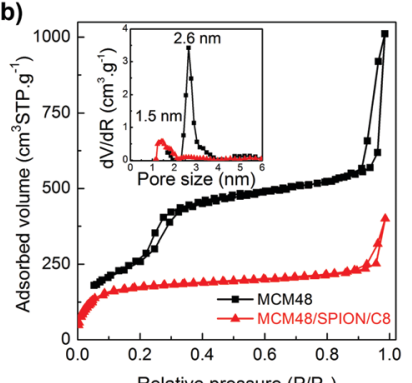

(d)

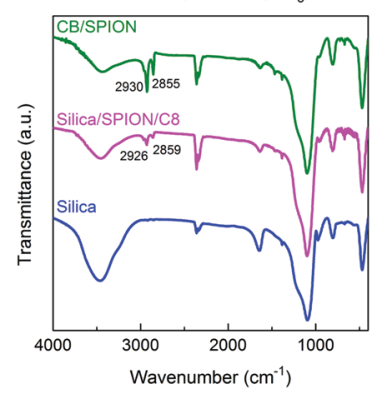

Fig. 2 ( $a$ and d) FTIR spectra and ( $b$ and $c$ ) nitrogen adsorptiondesorption isotherms of: $\mathrm{CB} / \mathrm{SPION}$ (green line), pristine $\mathrm{SiO}_{2}$ (blue line), $\mathrm{SiO}_{2} / \mathrm{SPION} / \mathrm{C} 8$ (pink line), pristine MCM48 (black line), and MCM48/ SPION/C8 (red line). The corresponding BJH pore size distribution is depicted in the insets.

was previously described in our work on magnetic zeolites for wastewater treatment. ${ }^{35}$

The comparative FTIR spectra of commercial $\mathrm{SiO}_{2}$ and the synthesized MCM48 depict similar peaks (see Fig. 2). The bands at $3443 \mathrm{~cm}^{-1}$ and $1640 \mathrm{~cm}^{-1}$ are characteristic of the stretching and bending modes of water adsorbed in silica materials, ${ }^{36}$ respectively, which are known to be good desiccant agents. The shoulder observed at $3250 \mathrm{~cm}^{-1}$ on the broad water stretching band is attributed to the silanol groups $\mathrm{O}-\mathrm{H}$ stretching modes. The signals observed at $1235 \mathrm{~cm}^{-1}$ and $1085 \mathrm{~cm}^{-1}$ are assigned to the longitudinal and transversal asymmetric stretching modes of the Si-O-Si bonds, respectively, whereas the symmetric stretching mode band was found at $800 \mathrm{~cm}^{-1}$. $^{36}$ The band at $966 \mathrm{~cm}^{-1}$ is characteristic of the silanol group ( $\mathrm{Si}-\mathrm{OH}$ ) stretching mode. ${ }^{36}$ It should be noted that the intensity of this signal is much larger in MCM48 due to its enhanced surface area, which results in a larger number of terminal silanol groups per adsorbent mass. Finally, the clear peak at $460 \mathrm{~cm}^{-1}$ is assigned to the O-Si-O bending mode. ${ }^{36}$ These same typical silica FTIR peaks are observed in the organo-functionalized $\mathrm{SiO}_{2} / \mathrm{SPION} / \mathrm{C} 8$ and MCM48/SPION/C8 nanocomposites, but with much lower relative intensities, as expected for the presence of an organic layer on the silica particles, ${ }^{36}$ giving rise to new bands in the FTIR spectra. For example, the new peaks observed at $2924 \mathrm{~cm}^{-1}$ and $2854 \mathrm{~cm}^{-1}$ are associated with the $\mathrm{C}-\mathrm{H}$ stretching modes, ${ }^{37}$ which indicate the successful functionalization of the surface with alkyl chains.

To demonstrate the efficient functionalization of the silicabased materials, TGA was conducted (see Fig. S2, ESI $\dagger$ ). The initial mass loss event in the temperature range of $30{ }^{\circ} \mathrm{C}$ to

$150{ }^{\circ} \mathrm{C}$ is associated with the loss of adsorbed water, as observed also in the control sample. The second region from $150{ }^{\circ} \mathrm{C}$ to $700{ }^{\circ} \mathrm{C}$ is associated with the thermal decomposition of the alkyl chains and their combustion into $\mathrm{CO} / \mathrm{CO}_{2}$ and water. No appreciable change in mass was observed in the range of $700{ }^{\circ} \mathrm{C}$ to $800{ }^{\circ} \mathrm{C}$, as expected for the complete removal of organic species from the composite materials. Thus, the loss of mass in the second region was used to calculate the percentage of organic fraction incorporated in the composite materials (13.0 wt\% for $\mathrm{SiO}_{2} / \mathrm{SPION} / \mathrm{C} 8,13.8 \mathrm{wt} \%$ for MCM48/SPION/C8, and $17.4 \mathrm{wt} \%$ for commercial $\mathrm{CB} / \mathrm{SPION}$ ), thus demonstrating the effective functionalization of the adsorbents by organosilanes. It should be noted that no change in mass was observed for the pristine silica gel used as a control above $150{ }^{\circ} \mathrm{C}$, validating the measurements.

The nitrogen adsorption-desorption isotherms of the pristine silica adsorbents ( $\mathrm{SiO}_{2}$ and MCM48) and their nano-enabled composites are depicted in Fig. 2. It can be seen in Fig. $2 b$ that commercial silica gel 60 presents a type IV isotherm with $\mathrm{H} 2$ hysteresis, which is characteristic of materials with bottle-neck pores, with a BET surface area $\left(S_{\mathrm{BET}}\right)$ of $617 \mathrm{~m}^{2} \mathrm{~g}^{-1}$ and a pore size of $\sim 4.4 \mathrm{~nm}$. In contrast, the synthesized MCM48 silica presents a type IV isotherm with $\mathrm{H} 1$ type hysteresis, which is characteristic of highly organized mesoporous materials with a defined pore size and homogeneous distribution. MCM48 presented a 2-fold larger $S_{\text {BET }}$ of $1212 \mathrm{~m}^{2} \mathrm{~g}^{-1}$ and pore size of $2.6 \mathrm{~nm}$ ( $c f$. inset panel Fig. 2c), consistent with the higher intensity of the Si-OH FTIR stretching signal at $966 \mathrm{~cm}^{-1}$ compared to silica gel 60 ( $c a$. half peak intensity). Accordingly, MCM48 is a more porous material with a pore volume of $1.56 \mathrm{~cm}^{3} \mathrm{~g}^{-1}$ than silica gel with $0.81 \mathrm{~cm}^{3} \mathrm{~g}^{-1}$. The functionalization of both silica materials resulted in a decrease in the $S_{\mathrm{BET}}$, pore size and volume to less than half the respective initial values. $\mathrm{SiO}_{2} / \mathrm{SPION} / \mathrm{C} 8$ presented an $S_{\mathrm{BET}}$ of $386 \mathrm{~m}^{2} \mathrm{~g}^{-1}$, pore size of $2.3 \mathrm{~nm}$ and pore volume of $0.46 \mathrm{~cm}^{3} \mathrm{~g}^{-1}$, whilst MCM48/SPION/C8 presented an $S_{\mathrm{BET}}$ of $560 \mathrm{~m}^{2} \mathrm{~g}^{-1}$, pore size of $1.5 \mathrm{~nm}$ and pore volume of $0.62 \mathrm{~cm}^{3} \mathrm{~g}^{-1}$. It is important to note that even after organofunctionalization, MCM48/SPION/C8 presented an $S_{\mathrm{BET}}$ area twice that of the commercial CB/SPION ( $S_{\text {BET }}$ of $201 \mathrm{~m}^{2} \mathrm{~g}^{-1}$ ). The decrease in pore size observed in the composite materials can be explained by the functionalization of their internal pores by alkyl chains, ${ }^{37}$ which seem to be beneficial to increase the affinity towards target BTEX adsorption for extraction.

The SEM images (Fig. 3) show the homogeneous size distribution of the three silica-based materials considered in this work. $\mathrm{CB} / \mathrm{SPION}$ and $\mathrm{SiO}_{2} / \mathrm{SPION} / \mathrm{C} 8$ have rock-shaped particles with an average size of $60 \mu \mathrm{m}$, whereas MCM48/SPION/C8 is constituted by spheroidal particles with an average size of $116 \mathrm{~nm}$ and homogeneous distribution.

The MCM48/SPION/C8 nanocomposite was further analysed by TEM and aberration-corrected STEM, as shown in Fig. 4. It can be observed in Fig. 4a that the spherical particles present a homogeneous distribution of $116 \pm 15 \mathrm{~nm}$ diameter particles, in agreement with the dynamic light scattering (DLS) measurements and the previous SEM images. Further magnification of the particles in dark-field mode (see Fig. 4b) showed the highly 

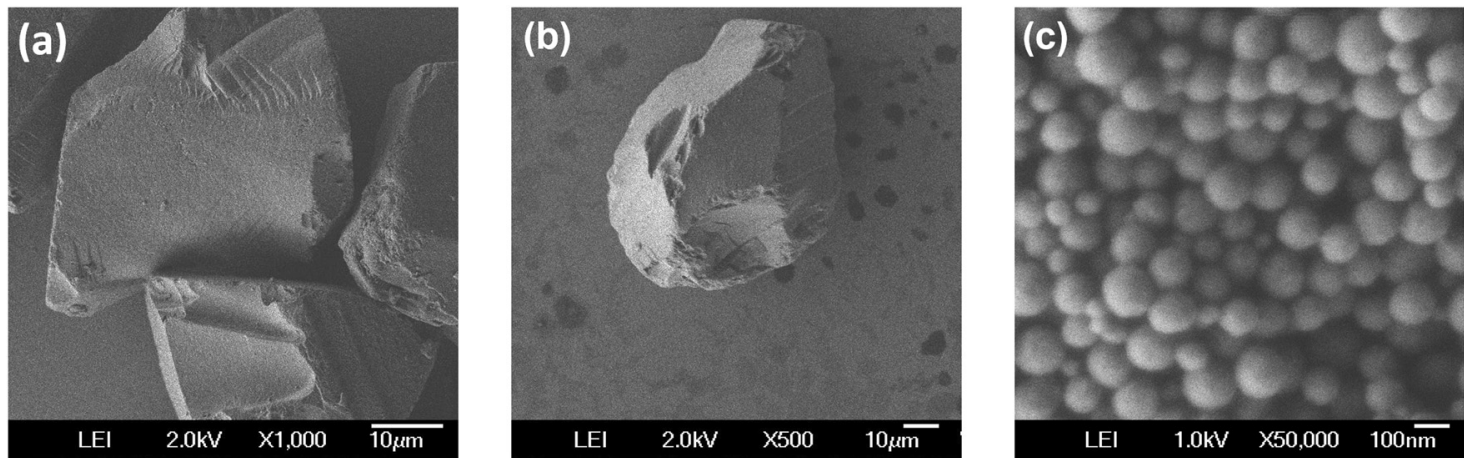

Fig. 3 Scanning electron microscopy (SEM) images of (a) commercial CB/SPION, (b) $\mathrm{SiO}_{2} / \mathrm{SPION} / \mathrm{C} 8$, and (c) MCM48/SPION/C8

organized porous structure of the material, which is also consistent with the previously discussed analyses. The interplanar distance of $3.4 \pm 0.2 \mathrm{~nm}$ defined by the pores is compatible with the $3.6 \mathrm{~nm}$ spacing determined by XRD analysis for that same parameter. The inset panel of Fig. $4 \mathrm{~b}$ depicts an organized porous structure, consistent with a pore size of $2.1 \pm 0.2 \mathrm{~nm}$ and the nitrogen adsorption-desorption behaviour depicted in Fig. 2. The images shown in Fig. 4d-f evidence the MCM48 surface decoration with small $7 \mathrm{~nm}$ large SPIONs, which are clearly defined in the TEM bright-field and high-angle annular dark-field (HAADF) images. Further analysis by HRTEM (see Fig. S3, ESI $\dagger$ ) identified constructive interferences, indicating the high crystallinity of the magnetite nanoparticles.

The spacings of the constructive interference fringes in Fig. S4 (ESI $\dagger$ ) are $0.207 \mathrm{~nm}, 0.251 \mathrm{~nm}$, and $0.293 \mathrm{~nm}$, corresponding to the crystallographic (400), (311) and (220) planes ${ }^{29}$ respectively, which are characteristic of the cubic spinel structure of magnetite $\left(\mathrm{Fe}_{3} \mathrm{O}_{4}\right)$, as depicted in the XRD patterns shown in Fig. 1.

The elemental mapping conducted by EDS (Fig. 5) analysed the distribution of $\mathrm{Fe}, \mathrm{O}, \mathrm{Si}$, and $\mathrm{C}$ in the STEM images collected under HAADF mode. It can be clearly seen by comparing the elemental mappings that there is a correlation between the position of $\mathrm{Si}, \mathrm{O}$, and $\mathrm{C}$. This suggests a uniform distribution

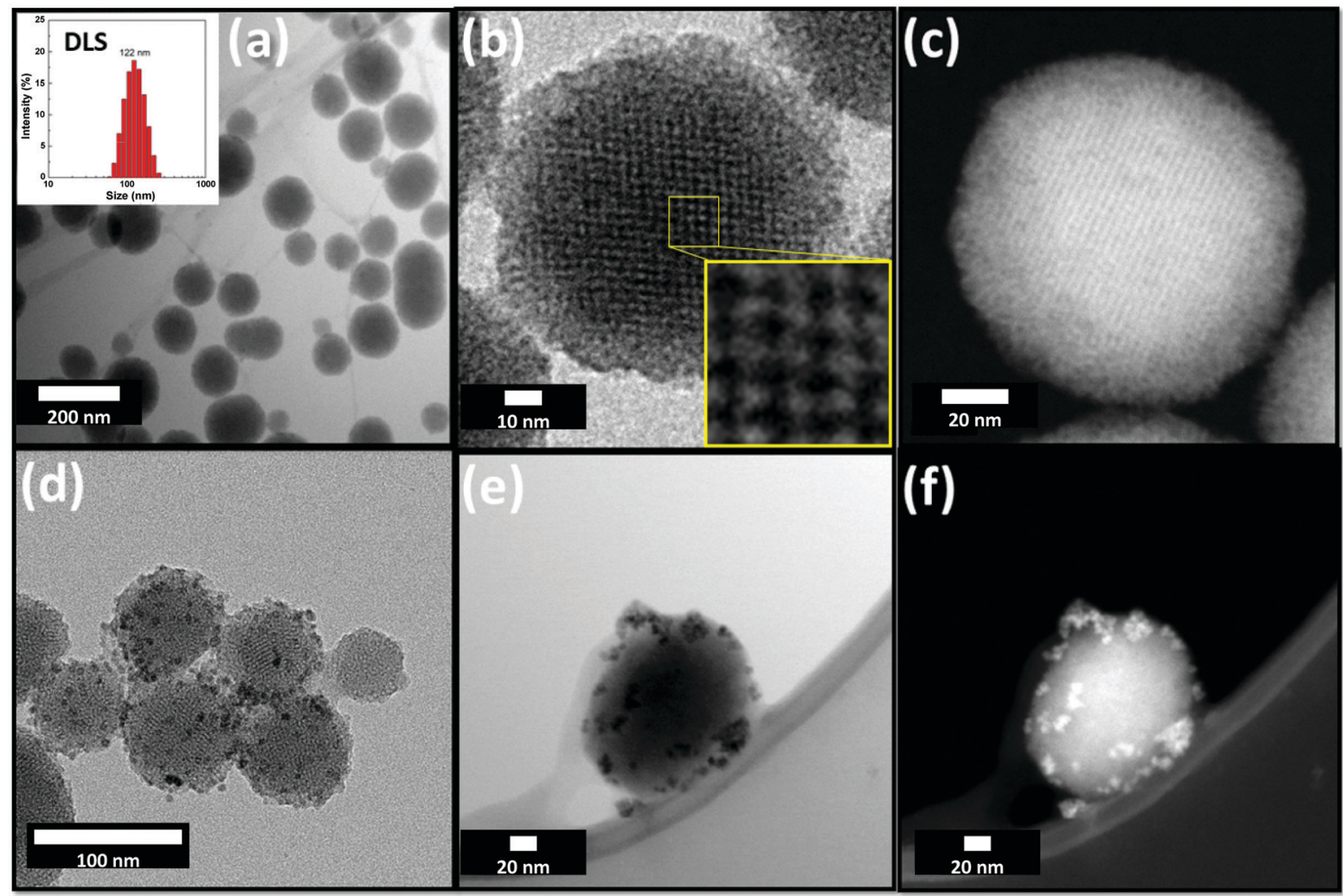

Fig. 4 Transmission electron microscopy of (a-c) pristine MCM48 and ( $d-f$ ) nanocomposite MCM48/SPION/C8. (a and d) CTEM images, (b) HRTEM image, ( $c$ and f) STEM images in HAADF mode, and (e) STEM image in BF mode. The inset panel in (a) shows the size distribution histogram determined by dynamic light scattering analysis. 
of C8 on the MCM48 surface, as expected for the bonding of the alkylsilane on the silica surface, forming covalent $\mathrm{Si}-\mathrm{O}-\mathrm{Si}-\mathrm{C} 8$ bonds. The mapping of $\mathrm{Fe}$ indicates unequivocally that the external surface of the MCM48 particles is decorated uniformly by SPIONs.

\section{Benchmarking BTEX adsorption of silica-based materials and nanocomposites}

Silica gel-based magnetic nanocomposite. Adsorption capacity as a function of concentration is one of the most important parameters to evaluate the performance of adsorbent materials. Silica gel 60 was used as a standard due to its wide use as an adsorbent in chromatography and similarity with the composite materials, thus providing a suitable standard for the present work. Accordingly, the adsorption isotherms for BTEX were obtained for the nano-enabled adsorbent composites in comparison with commercially available materials as standards, more specifically, organofunctionalized Chromabond PAH silica particles decorated with SPIONs (CB/SPION). The adsorption isotherms of the different BTEX components in $\mathrm{CB} / \mathrm{SPION}$ are shown in Fig. 6, while the calibration curves are presented in the ESI $\dagger$ (before and after the adsorption assay). The respective chromatograms confirming the very small amounts of benzene adsorbed by CB/SPION are shown in Fig. S5 (ESI $\dagger$ ), which at the detection limit of the equipment,

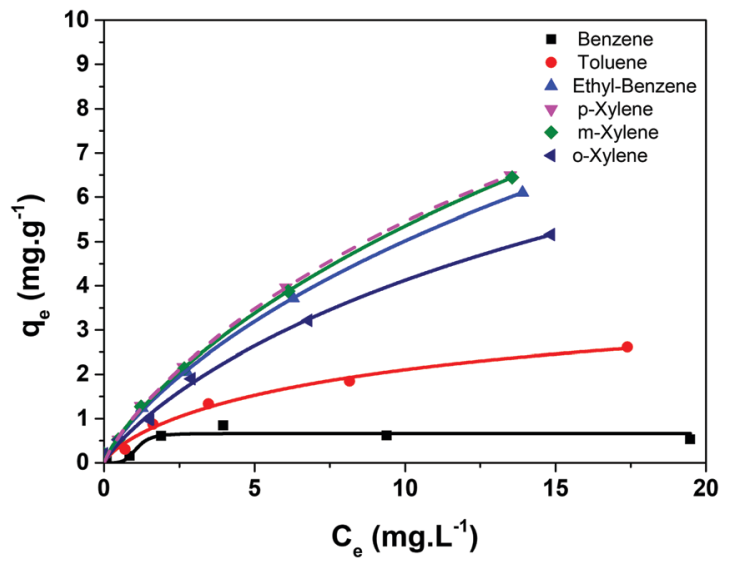

Fig. 6 Experimental points determined for the adsorption of BTEX on $\mathrm{CB} / \mathrm{SPION}$ and fitted using the Langmuir-Freundlich isotherm model (solid lines).

gave scattered data that made the isotherm fit unsuitable in a concentration range below $2 \mathrm{mg} \mathrm{\textrm {L } ^ { - 1 }}$.

Toluene, ethylbenzene and xylenes showed continuously ascending curve patterns of adsorption capacities, contrasting with the behaviour expected for a purely Langmuir isotherm model. In this case, saturation is expected when a monolayer of adsorbate is formed on the adsorbent, considering noninteracting adsorption sites. This simple model can be improved
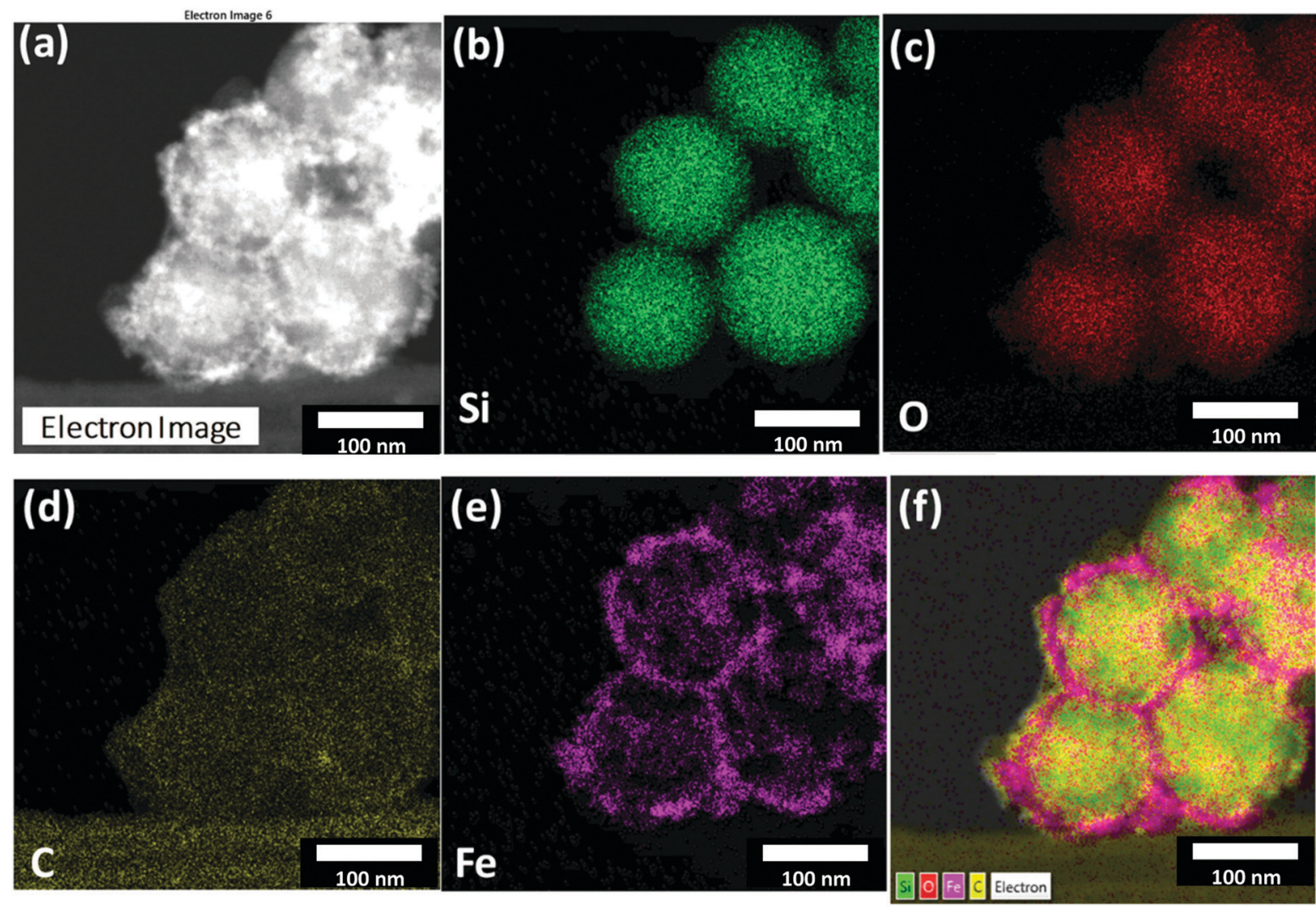

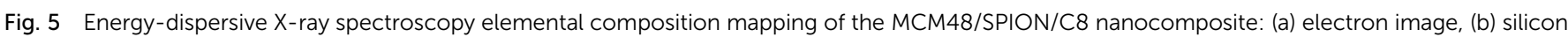

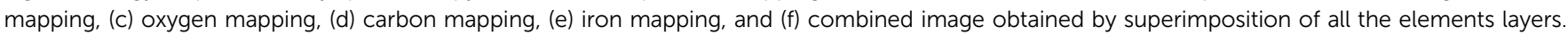


considering the possibility of secondary adsorbate-adsorbate interactions by adopting the hybrid Langmuir-Freundlich model. ${ }^{38}$ In the case of aromatic compounds, there is clear possibility of $\pi$-stacking interactions, which can lead to the formation of a second (or further) adsorption layer and a continuously increasing isotherm profile instead of a plateau, as observed in Fig. 6. The adsorption parameters determined by fitting the BTEX adsorption isotherms by applying the LangmuirFreundlich adsorption model are listed in Table 1.

As the hydrophobic character of a molecule increases, a higher tendency to interact with the adsorbent in detriment with water is expected. This occurs due to the very low miscibility of xylenes (almost immiscible with water) in comparison with toluene (water miscibility of $0.47 \mathrm{~g} \mathrm{~L}^{-1}$ ) and ethylbenzene (water miscibility of $0.15 \mathrm{~g} \mathrm{~L}^{-1}$ ). The high lipophilic character of these molecules should also improve their interaction with the organic fraction present in the organofunctionalized silica, allowing this material to adsorb them. However, the application of this material is strongly limited by its low surface area, characteristic of the micron dimensions of the particles, as discussed previously.

Mesoporous MCM-48 silica-based magnetic nanocomposite. The adsorption capabilities of the different materials were evaluated from their respective adsorption isotherms as shown in Fig. 7. The analysis of the experimental data determined by fitting with the Langmuir-Freundlich equation suggests the prior adsorption of BTEX compounds as a monolayer on the surface of the superparamagnetic adsorbent nanocomposites, then the possibility of adsorbate-adsorbate interactions, forming multilayers. It is noteworthy to mention that the pristine silica gel 60 and MCM-48 materials showed no adsorption capacity and selectivity towards BTEX in aqueous solution. This result demonstrates that organofunctionalization plays a fundamental role in ensuring the selective interaction of the target adsorbates (i.e., BTEX) with these adsorbents. This trend can be tentatively explained by the hydrophobic interactions of the C8-organic chains with the aromatic structures of BTEX, which stabilize their adsorption on the silica materials.
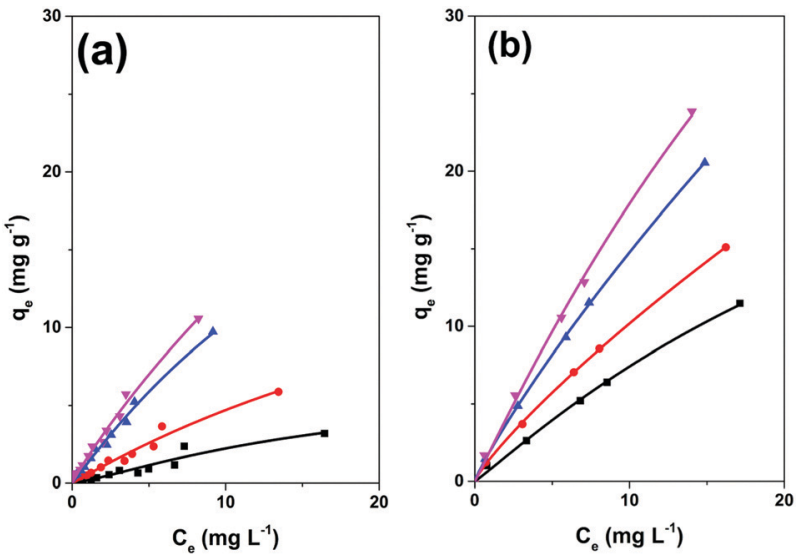

Fig. 7 Langmuir-Freundlich isotherms of adsorption of BTEX on (a) $\mathrm{SiO}_{2} /$ SPION/C8, and (b) MCM48/SPION/C8. ( $\mathbf{\square})$ Benzene, (O) toluene, ( $(\mathbf{\Delta})$ ethylbenzene, and $(\boldsymbol{\nabla})$ xylene.
Table 1 Adsorption parameters determined by fitting the CB/SPION adsorption isotherms of BTEX shown in Fig. 6 using the LangmuirFreundlich adsorption model

\begin{tabular}{lllll}
\hline Analyte & $Q_{\text {sat }}\left(\mathrm{mg} \mathrm{g}^{-1}\right)$ & $K_{\mathrm{LF}}\left(\mathrm{L} \mathrm{mg}^{-1}\right)$ & $n_{\mathrm{LF}}$ & $R^{2}$ \\
\hline Benzene & - & - & - & - \\
Toluene & 4.5 & 0.15 & 0.8 & 0.973 \\
Ethylbenzene & 21.9 & 0.05 & 0.8 & 0.997 \\
$m$-Xylene & 24.8 & 0.04 & 0.8 & 0.997 \\
$p$-Xylene & 19.8 & 0.06 & 0.8 & 0.997 \\
$o$-Xylene & 13.9 & 0.06 & 0.8 & 0.992 \\
\end{tabular}

The adsorption capacity $\left(Q_{\text {sat }}\right)$ calculated from the isotherms by fitting with the Langmuir-Freundlich equation is summarized in Table 2. It is important to note that the $Q_{\text {sat }}$ values of MCM48/ SPION/C8 are more than twice that of $\mathrm{CB} / \mathrm{SPION}$ and $\mathrm{SiO}_{2} / \mathrm{SPION} /$ $\mathrm{C} 8$, suggesting its improved performance for the extraction of BTEX from the aqueous phase. The higher $Q_{\text {sat }}$ values can be associated with its larger $S_{\mathrm{BET}}$ and the highly organized mesoporous structure of MCM48 spherical nanoparticles. These results are consistent with the enhanced performance and promising capabilities of MCM48/SPION/C8 as adsorbent for magnetic solidphase extraction for the sensitive and quantitative analysis of BTEX in complex water matrices.

Interestingly, the $Q_{\text {sat }}$ values for MCM48/SPION/C8 are more than three times that of $\mathrm{SiO}_{2} / \mathrm{SPION} / \mathrm{C} 8$ and much larger than that of $\mathrm{CB} / \mathrm{SPION}$. Considering the known insignificant affinity of silica materials for BTEX, the improved affinity can be explained by their $n$-octanol/water partition coefficients $\left(K_{\mathrm{OW}}\right)^{39}$ and improved interaction with the organofunctionalization layer. In this case, higher values of $K_{\mathrm{LF}}$ should be associated with lower affinities for water and a higher interaction with hydrophobic species such as the organofunctionalized C8 chains in the composites. However, in contrast with the expected results, the BTEX components presented a decrease in $K_{\mathrm{LF}}$ values from benzene (0.02), to toluene (0.005) and ethylbenzene (0.008), increasing again to xylenes $(0.02) .{ }^{40}$ This behaviour is a dramatic difference compared with the micrometric-sized $\mathrm{SiO}_{2} / \mathrm{SPION} / \mathrm{C} 8$ or the $\mathrm{CB} / \mathrm{SPION}$ composite, where the $K_{\mathrm{LF}}$ values nearly followed the tendency defined by the octanol/water partition coefficients. This result indicates that the main interactions responsible for the adsorption of the BTEX molecules on these silica-based composites is the organic layer (C8).

Table 2 Benchmarking adsorption capacity $\left(Q_{\text {sat }}\right)$ estimated by the LangmuirFreundlich isotherm analysis. Synthesized MCM48/SPION/C8 adsorbent outperformed the $Q_{\text {sat }}$ value of commercial CB/SPION

\begin{tabular}{llclll}
\hline & & \multicolumn{2}{c}{ Langmuir-Freundlich isotherm } \\
\cline { 3 - 6 } Adsorbent & Analyte & $Q_{\text {sat }}\left(\mathrm{mg} \mathrm{g}^{-1}\right)$ & $K_{\mathrm{LF}}\left(\mathrm{L} \mathrm{mg}^{1}\right)$ & $n_{\mathrm{LF}}$ & $R^{2}$ \\
\hline $\mathrm{SiO}_{2} /$ SPION/C8 & Benzene & 6.7 & 0.02 & 1.3 & 0.999 \\
& Toluene & 21.8 & 0.03 & 1.0 & 0.999 \\
& Ethylbenzene & 37.9 & 0.03 & 1.0 & 0.999 \\
& Xylene & 80.2 & 0.02 & 0.9 & 0.999 \\
$\mathrm{MCM} 48 /$ SPION/C8 8 & Benzene & 40.3 & 0.02 & 1 & 0.996 \\
& Toluene & 290.9 & 0.005 & 0.9 & 0.999 \\
& Ethylbenzene & 244.1 & 0.008 & 0.9 & 0.999 \\
& Xylene & 93.1 & 0.02 & 1 & 0.997
\end{tabular}


The contrasting tendency observed for MCM48/SPION/C8 suggests that the interaction sites should be highly hydrophilic and based on silica, as reinforced by its much lower $K_{\mathrm{LF}}$ value (Table 2). However, it is interesting to emphasize that the significantly higher surface area of the MCM48-based nanocomposite than the other silica materials will proportionally increase the number of active sites, thus contributing to the decrease in the $K_{\mathrm{LF}}$ value. Surprisingly, the MCM48-based magnetic nanoadsorbents prepared in the present work outperformed the adsorption capacity of analogous organofunctionalized CB/SPION and $\mathrm{SiO}_{2} / \mathrm{SPION} / \mathrm{C} 8$. Here, it is important to remember that in contrast with these materials, MCM48/SPION/C8 has two distinct adsorption sites given that both the binding of SPIONs and the organofunctionalization process occurred essentially at the mesoporous silica grain surface. However, this hydrophobic outer layer does not seem to significantly contribute to the adsorption capacity, but rather mainly increases the affinity of the particle for BTEX molecules, ensuring their approach and entrance into the MCM48 pores, where they become trapped. In fact, the porous volume is much larger than in the microparticles given the enhanced specific surface area. This means that the $K_{\mathrm{LF}}$ values essentially reflect the interaction of BTEX with the mesoporous silica inner pores rather than with the hydrophobic organofuntionalized layer, which seems to just perturb the equilibrium in a way to induce the entrapment of these organic molecules in the porous structure, as successfully described by the hybrid Langmuir-Freundlich adsorption model considering the presence of different adsorption sites and interaction modes. Briefly, the hydrophobic interactions with the organic layer are the most relevant phenomenon in the micrometric silica nanocomposite materials, but the secondary adsorbate-adsorbate interactions in the nanoporous volume seem to play a significant role in the adsorption of BTEX in MCM48/SPION/C8.

Similar $Q_{\text {sat }}$ behaviour with contrasting $K_{\mathrm{LF}}$ values has been previously described in the literature. ${ }^{25,41}$

Pre-concentration of BTEX by magnetic solid-phase extraction. BTEX quantification in water samples is generally limited by the low concentrations of these compounds in complex water matrices. Thus, pre-concentration through extraction processes is required to preconcentrate these compounds in organic solvents for GC-MS analyses. Commercial adsorbents for solidphase extraction may present low recovery rates due to (i) the low adsorbent-adsorbate affinity for the extraction process and (ii) the low efficiency of the recovery process. In fact, both parameters must be fine-tuned to ensure good adsorption and recovery, where the latter is the major issue for commercial carbon-based adsorbents for BTEX pre-concentration. ${ }^{42}$

The tailored capabilities of the synthesized nanocomposite materials were benchmarked by analysing their solid-phase extraction performance using a non-polluted real water sample collected in a gas station spiked with $3.0 \mu \mathrm{g} \mathrm{\textrm {L } ^ { - 1 }}$ of BTEX. These experiments involved the treatment of $10 \mathrm{~mL}$ of water sample, in which a defined mass of adsorbent was introduced as a slurry and maintained under stirring for $5 \mathrm{~min}$. The adsorbent particles were then magnetically recovered and BTEX was extracted with $1.0 \mathrm{~mL}$ of dichloromethane, which represents a 10-fold preconcentration factor up to $30 \mu \mathrm{g} \mathrm{\textrm {L } ^ { - 1 }}$ of BTEX.

A mass of $30 \mathrm{mg}$ of adsorbent was required to recover $100 \%$ of $3.0 \mu \mathrm{g} \mathrm{L}^{-1}$ of BTEX spiked in $10 \mathrm{~mL}$ of aqueous sample, as shown in Fig. 8a. It should be noted that the mass required to reach complete extraction by MCM48/SPION/C8 was significantly lower than that for CB/SPION (see Fig. 8b) since it presents a much larger adsorption capacity towards BTEX as a result of the confinement effect induced by the alkyl functionalization of the highly ordered mesoporous silica nanoparticles. Indeed, it has a much higher $S_{\mathrm{BET}}$, which is responsible for the proportional reduction in mass required for adsorption/concentration in comparison to the commercial adsorbents (see Table 1), a trend that can be explained by the direct relationship between extraction capacity and the concentration of adsorption sites available on its surface. It was observed that the initial concentration of BTEX could be completely adsorbed and recovered with dichloromethane. Therefore, the synthesized MCM48/SPION/C8 exhibited a
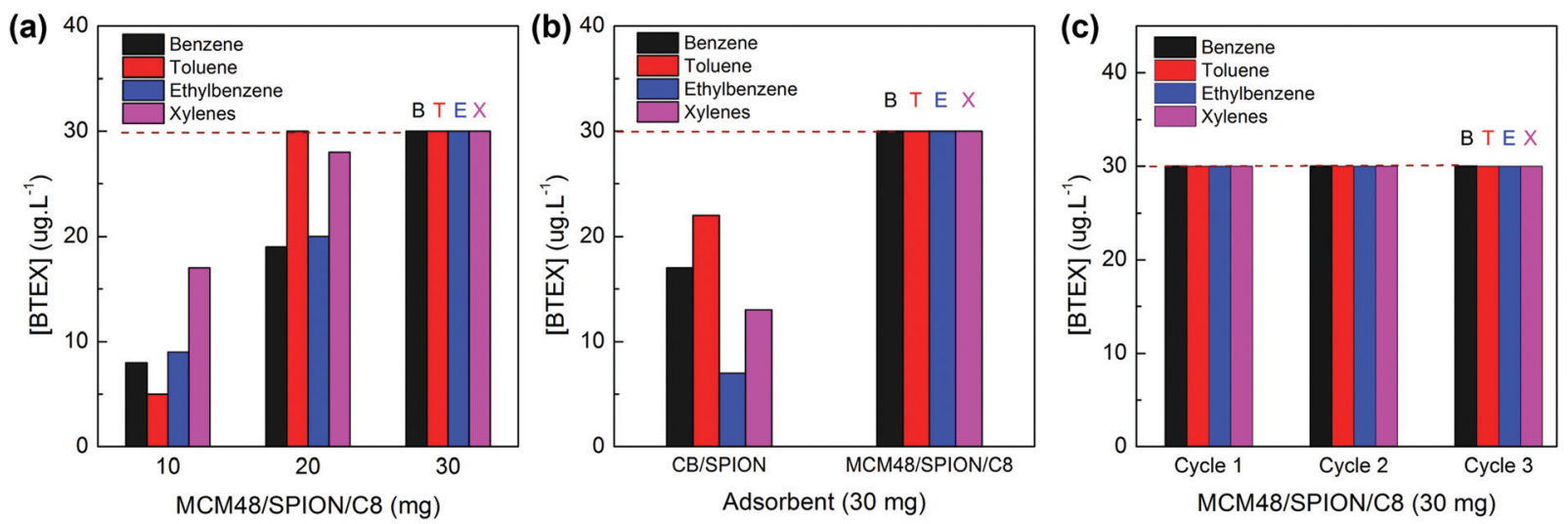

Fig. 8 Magnetic solid-phase extraction from $10 \mathrm{~mL}$ sample containing $3.0 \mu \mathrm{g} \mathrm{L}^{-1}$ of BTEX. Extraction process with $1.0 \mathrm{~mL}$ of dichloromethane resulted in a preconcentration factor of 10 -fold up to $30.0 \mu \mathrm{g} \mathrm{L}^{-1}$ of BTEX. (a) Evaluation of the adsorbent mass requirement to recover $100 \%$ of BTEX. (b) Comparative BTEX recovery efficiency using an identical mass ( $30 \mathrm{mg}$ ) of CB/SPION and MCM48/SPION/C 8 adsorbents. (c) Performance of magnetic MCM48/SPION/C8 adsorbent during three consecutive cycles of magnetic solid-phase extraction, recycling and reuse. 
superior recovery performance compared with that of commercially available products for solid-phase extraction. Furthermore, the easy magnetic recovery enabled the so-called magnetic solidphase extraction method, which demonstrated interesting features such as faster analysis, lower consumption of solvents and the possibility of adsorbent reuse in several extraction cycles for different samples analyses, as depicted in Fig. 8c, where reproducible extraction efficiencies were demonstrated for up to three cycles of adsorbent regeneration and reuse.

In Table 3, the adsorption capacity of MCM48/SPION/C8 is compared with that of typical adsorbents reported in the literature. The $Q_{\text {sat }}$ values for BETX are similar but more equilibrated than that presented by the organofunctionalized mesoporous silica, suggesting that the reported adsorbents are more suitable for preconcentration purposes. In addition, our nanocomposite material presents exclusive superparamagnetic properties, i.e., has tailored adsorption capacities for the preconcentration and recovery of BTEX, while incorporating the possibility of magnetic separation, thus realizing the mSPE method for the analysis of BTEX water contaminants.

\section{Experimental}

\section{Chemicals}

Tetraethyl orthosilicate (TEOS, 98\% v/v), hexadecyltrimethylammonium bromide (CTAB, $\geq 98 \%$ ), triethoxy(octyl)silane (GC grade, $\geq 95 \%$ ), and Pluronic P123 copolymer were purchased from Sigma Aldrich. Commercial silica gel 60 was acquired from Sigma-Aldrich. Chromabond ${ }^{\mathbb{R}} \mathrm{C} 18 \mathrm{PAH}$ (CB), a commercial silica-based adsorbent functionalized with octadecyl groups, was used as the control in the BTEX extraction (Macherey-Nagel Company). The benzene, toluene, ethylbenzene, and xylene (BTEX) standard solutions used in the measurements were supplied by Sigma-Aldrich. Ammonium hydroxide $(28 \% \mathrm{v} / \mathrm{v})$, ethanol, and acetone, all of analytical grade purity, were supplied by LABSYNTH (Brazil). All solutions were prepared using ultrapure water from a Millipore Milli-Q system with a resistivity $>18.2 \mathrm{M} \Omega \mathrm{cm}$ at $25{ }^{\circ} \mathrm{C}$.

\section{Synthesis of magnetic silica adsorbents}

MCM48 mesoporous silica nanoparticles were prepared at room temperature via the combination of a template method with a modified Stöber method. ${ }^{33}$ A bisurfactant system consisting of $2.0 \mathrm{~g}$ of Pluronic P123 and $0.5 \mathrm{~g}$ of CTAB in a mixture of $50 \mathrm{~mL}$ ethanol, $112.5 \mathrm{~mL}$ deionized (DI) water and $12.5 \mathrm{~mL}$ ammonium hydroxide was used as the reaction medium. The template was formed when the concentration of CTAB was higher than its the critical micelle concentration $(13.8 \mathrm{mM})$ but was adjusted to be high enough to restructure itself in $3 \mathrm{D}$ cubic patterns, which were used as a template for the preparation of the mesoporous materials, as schematically shown in Fig. 9a. Pluronic P123 acted as a stabilizer and directed the growth of the silica particles in a spherical shape. Then, $1.93 \mathrm{~mL}$ of TEOS was added to initiate silica nucleation and deposition on the template. After the addition of the silica precursor, the solution was kept under vigorous stirring for $1 \mathrm{~min}$. The white slurry formed was left to settle for $24 \mathrm{~h}$ in the reactor vessel to complete the crystallization of ordered mesoporous silica. Solid nanoparticles were separated by centrifugation at $13000 \mathrm{rpm}$ for $40 \mathrm{~min}$. The recovered solid was washed repeatedly with ethanol and dried at $80{ }^{\circ} \mathrm{C}$ for $8 \mathrm{~h}$. The resulting powder was refluxed in a washing solution of hydrochloric acid and ethanol (3 mL HCl:100 mL ethanol), which allowed complete removal of the bisurfactant template, producing a material with structural characteristics compatible with MCM48, an ordered-mesoporous silica, as discussed below. ${ }^{32,33}$

Commercial silica gel 60, commercial CB, and synthesized MCM48 ordered-mesoporous silica were nano-enabled with pre-synthesized $7 \mathrm{~nm}$ diameter superparamagnetic iron oxide nanoparticles (SPIONs). ${ }^{46}$ SPIONs were prepared via the thermo-decomposition of an iron(III) precursor in a high boiling temperature solvent. ${ }^{47-49}$ Briefly, $23.3 \mathrm{~g}$ of iron(III) salt $(0.10 \mathrm{~mol})$ was solubilized and heated to $180{ }^{\circ} \mathrm{C}$ for $30 \mathrm{~min}$, and then, the temperature was increased to $230{ }^{\circ} \mathrm{C}$ for $30 \mathrm{~min}$. After cooling, the product was precipitated with tetrahydrofuran (THF) and the black solid was isolated using an $\mathrm{Nd}_{2} \mathrm{Fe}_{14} \mathrm{~B}$ magnet. Purification was carried out by successive cycles of

Table 3 Benchmarking adsorption capacity $\left(Q_{\text {sat }}\right)$ obtained by other authors

\begin{tabular}{|c|c|c|c|}
\hline Adsorbent & Analyte & $Q_{\text {sat }}\left(\mathrm{mg} \mathrm{g}^{-1}\right)$ & Ref. \\
\hline Modified ordered mesoporous carbon (OMC) & $\begin{array}{l}\text { Benzene } \\
\text { Toluene } \\
\text { Ethylbenzene } \\
\text { Xylene }\end{array}$ & $\begin{array}{r}7.6 \\
24.2 \\
35.6 \\
49.2\end{array}$ & 43 \\
\hline Nickel-modified zeolite $4 \mathrm{~A}$ & $\begin{array}{l}\text { Benzene } \\
\text { Toluene } \\
\text { Ethylbenzene } \\
\text { Xylene }\end{array}$ & $\begin{array}{c}1.3 \\
1.2 \\
- \\
1.2\end{array}$ & 44 \\
\hline Surface-functionalized mesoporous silica nanoparticles & $\begin{array}{l}\text { Benzene } \\
\text { Toluene } \\
\text { Ethylbenzene } \\
\text { p-Xylene } \\
\text { Benzene }\end{array}$ & $\begin{array}{r}18.0 \\
84.8 \\
296.2 \\
392.8 \\
40.3\end{array}$ & 45 \\
\hline MCM48/SPION/C8 & $\begin{array}{l}\text { Toluene } \\
\text { Ethylbenzene } \\
\text { Xylene }\end{array}$ & $\begin{array}{r}290.9 \\
244.1 \\
93.1\end{array}$ & This work \\
\hline
\end{tabular}




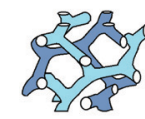

3D cubic template 3D cubic template
induced by CTAB

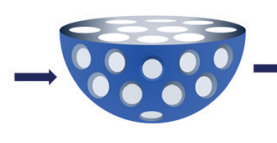
Highly ordered mesoporous silica

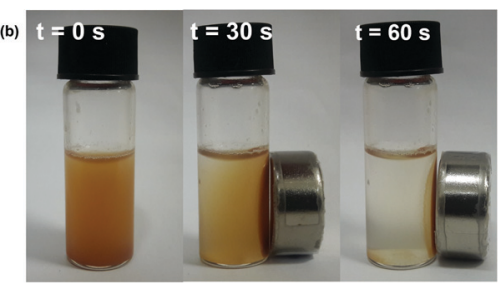

Fig. 9 (a) Cubic structures formed by CTAB above critical micellar concentration used as a template to generate highly ordered mesoporous silica. (b) Photo showing the magnetic recovery of MCM48/SPION/C 8 nanocomposite in $60 \mathrm{~s}$.

redispersion of the solid in small volumes of water and precipitation with an equal volume of THF.

Functionalization of the adsorbents with SPIONs enabled magnetic recovery of the saturated adsorbents after BTEX extraction. The nanocomposites were prepared by mixing $900 \mathrm{mg}$ of silica with $100 \mathrm{mg}$ of SPIONs under vigorous stirring in an ethanol: water $1: 1$ mixture for $1 \mathrm{~h}$, allowing their physical attachment on the adsorbent particles. The recovered solid was washed with acetone, water, and heated at $100{ }^{\circ} \mathrm{C}$ for $8 \mathrm{~h}$. A similar procedure was followed for the magnetic functionalization of the commercial CB adsorbent and MCM48. Fig. 9b depicts the quick magnetic recovery of the nano-enabled silica $\left(\mathrm{SiO}_{2} / \mathrm{SPION}, \mathrm{CB} /\right.$ SPION and MCM48/SPION) in $60 \mathrm{~s}$.

\section{Organo-functionalization of silica nanocomposites}

The magnetic nanocomposite adsorbents were functionalized with organic sidechains to enhance their hydrophobicity and selectivity towards aromatic compounds such as BTEX. Organic chains were attached to the silicon particles surface through silanization reaction using triethoxy(octyl)silane (C8) as an organo-silane precursor. The preparation process involved the dispersion of $0.8 \mathrm{~g}$ of silica nanocomposite in toluene with $20 \mathrm{wt} \%$ of organic precursor in the presence of $5 \mathrm{wt} \%$ of imidazole, which acted as a strong base to deprotonate the $\mathrm{Si}-\mathrm{OH}$ terminations on the silica surface. This process enhanced the reactivity of the silanol groups, leading to the formation of covalent $-\mathrm{Si}-\mathrm{O}-\mathrm{Si}-$ bonds with the organosilane molecules. The mixture was kept under reflux for $4 \mathrm{~h}$ to ensure complete functionalization.

\section{Characterization and instruments used in BTEX extraction analysis}

The silica-based adsorbents and nanocomposites were characterized using a Bruker Discover D8 X-ray diffractometer equipped with a $\mathrm{Cu}(\mathrm{K} \alpha)$ source set at $30 \mathrm{kV}$. FTIR measurements were recorded using a Bruker Alpha FTIR spectrophotometer in transmittance mode in the range of 400 to $4000 \mathrm{~cm}^{-1}$. The specific surface and textural properties of the nanocomposite adsorbents were analysed using nitrogen adsorption-desorption isotherms measured on a Quantachrome Nova 1200e Instrument. The samples were degassed under vacuum at $130{ }^{\circ} \mathrm{C}$ and the isotherms recorded at liquid nitrogen temperature $(77 \mathrm{~K})$, under low pressures $\left(10^{-4}-10^{-8}\right.$ Torr $)$. The specific surface area was calculated using the BET method. The pore size distribution was determined either using the Barrett-Joyner-Halenda method $(\mathrm{BJH})^{50}$ or the DFT method. ${ }^{51}$ Thermogravimetric analysis (TGA) was performed on a Shimadzu TGA Q500 instrument using

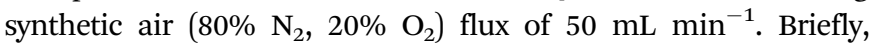
$5 \mathrm{mg}$ sample was placed in a platinum pan and equilibrated to $35{ }^{\circ} \mathrm{C}$ in the TGA prior to the application of a heating ramp of $5{ }^{\circ} \mathrm{C} \min ^{-1}$ up to $800{ }^{\circ} \mathrm{C}$.

Scanning electron microscopy (SEM) images were acquired using a JEOL JSM-7401F FESEM microscope. Transmission electron microscopy (TEM) and scanning transmission electron microscopy (STEM) images of the nanocomposites were obtained on a JEOL JSM-FEG 7401F. Elemental mapping was recorded by energy dispersive X-ray spectroscopy (EDS) using an X-MaxN 80 TLE silicon drift detector (SDD).

BTEX adsorption tests on the commercial silica-based nanocomposite (CB/SPION) were carried out using $10 \mathrm{~mL}$ of BTEX aqueous solution with concentrations in the range of $100 \mu \mathrm{g} \mathrm{L}^{-1}$ to $20 \mathrm{mg} \mathrm{L}^{-1}$, which were submitted to adsorption assays with $10 \mathrm{mg}$ of CB/SPION in a vortex mixer for $30 \mathrm{~min}$, and the solid was separated from the solution with the aid of a neodymiumbased magnet. To quantify the total amount of adsorbed material, the solution before and after the adsorption process was injected in a Shimadzu GC-17A V3 gas chromatography (GC-MS) coupled to a Shimadzu QP5050A mass spectrometer equipped with an Agilent DB-WAX $30 \mathrm{~m} \times 0.25 \mathrm{~mm} \times 0.25 \mu \mathrm{m}$ capillary column, using 99 999\% Helium as the carrier gas at a flow rate of $2.4 \mathrm{~mL} \mathrm{~min}{ }^{-1}$. The injection pressure was set to $20.0 \mathrm{kPa}$, the injector and interface temperature to $250{ }^{\circ} \mathrm{C}$, and the column temperature to $36{ }^{\circ} \mathrm{C}$ (hold $\left.3 \mathrm{~min}\right) / 90{ }^{\circ} \mathrm{C}\left(11{ }^{\circ} \mathrm{C} \mathrm{min}^{-1} /\right.$ hold $\left.3 \mathrm{~min}\right)$.

The BTEX adsorption tests were conducted using solutions with concentrations in the range of 1 to $20 \mathrm{mg} \mathrm{L}^{-1}$. Higher concentrations would not be realistic nor representative of natural water samples contaminated with BTEX. ${ }^{25}$ Furthermore, it should be noted that BTEX is easily volatilized from water solutions when present at much higher concentrations and would result in experimental error due to underestimation of the extraction efficiency (i.e., volatilized BTEX cannot be extracted). The solid-phase extraction (SPE) experiments were conducted in a capped PTFE vial of $5 \mathrm{~mL}$ containing $4.5 \mathrm{~mL}$ of aqueous BTEX sample and $1 \mathrm{mg}$ of adsorbent. After $5 \mathrm{~min}$ of extraction under agitation, the magnetic adsorbents were recovered in $15 \mathrm{~s}$ using a neodymium magnet. The remaining solution was analysed by HPLC using a Shimadzu LC-20AT fitted with a Phenomenex column $(4.6 \mathrm{~mm} \times 250 \mathrm{~mm}, 5 \mu \mathrm{m})$ coupled to an SPD-M20A photodiode array detector set at $199 \mathrm{~nm}$. Aliquots of $10 \mu \mathrm{L}$ were analysed using an acetonitrile : water $(70: 30)$ mobile phase at $1.0 \mathrm{~mL} \mathrm{~min}^{-1}$ and thermostated at $30{ }^{\circ} \mathrm{C} .{ }^{52}$

Magnetic solid-phase extraction measurements were performed using water collected from a non-polluted underground water reservoir of a gas station in Sao Paulo city, which was 
spiked with up to $3.0 \mu \mathrm{g} \mathrm{L^{-1 }}$ of the BTEX standard to obtain contaminated water samples. The adsorption of BTEX was conducted by adding a defined mass of adsorbent to $10 \mathrm{~mL}$ of water sample, which was maintained under agitation for $5 \mathrm{~min}$ at room temperature, and then magnetically recovered. The adsorbed BTEX was recovered/extracted from the magnetic nanocomposites by adding $1 \mathrm{~mL}$ of dichloromethane under agitation for $1 \mathrm{~min}$. Then, the amount of BTEX was quantified by GC-MS using a Shimadzu QP5050A GCMS fitted with an Agilent DB-5ms column $(30 \mathrm{~m} \times 0.250 \mathrm{~mm} \times 0.25 \mu \mathrm{m})$ at $40{ }^{\circ} \mathrm{C}$ for $3 \mathrm{~min}$, followed by a heating ramp of $10{ }^{\circ} \mathrm{C} \mathrm{min}^{-1}$ up to $180{ }^{\circ} \mathrm{C}$. Aliquots of $1 \mu \mathrm{L}$ were injected under Splitless mode, setting the injector temperature to $270{ }^{\circ} \mathrm{C}$. MS detection was conducted under selected-ion monitoring (SIM) mode under pre-selected $\mathrm{m} / \mathrm{z}$ values associated with BTEX. ${ }^{15}$

\section{Conclusions}

A novel silica-based selective nanocomposite adsorbent was designed, prepared, organofunctionalized with octylsilane, and decorated with SPIONs to obtain a material that can be employed for efficient magnetic extraction and recovery methods, realizing an interesting alternative adsorbent material suitable for magnetic solid-phase extraction. This was achieved by using high surface area MCM48 mesoporous silica, with no affinity towards light weight aromatic contaminants at all, and incorporating a hydrophobic layer by organofunctionalization with octylsilane to tailor the adsorption/desorption properties, and then carefully decorating the grain surface with SPIONs to preserve most of the adsorption capacity, while implementing the possibility of magnetic recovery for quick analyte recovery, adsorbent recycling and reuse. The template-assisted method was employed to prepare highly organized mesoporous nanocomposite adsorbents suitable for BTEX solid-phase extraction from water samples, whose adsorption isotherms were well described by the Langmuir-Freundlich model. The MCM48/SPION/C8 nanocomposite outperformed the adsorbent materials based on commercial products for the solidphase extraction of BTEX from real water matrices. The improved removal capability is associated with its twice as large $S_{\mathrm{BET}}$ of highly organized hierarchical mesoporous silica structure and homogeneous porous distribution, properties that enhance the $Q_{\text {sat }}$ and adsorption properties for solid-phase extraction thanks to the presence of an octylsilane hydrophobic layer for compatibilization and entrapment of light aromatic compounds in its inner pores. The MCM48/SPION/C8 composite is a highly competitive alternative to commercial products, which can reduce the operational time for BTEX sample preconcentration by simplifying the recovery of dispersed adsorbent from a slurry by magnetic separation, while enabling recycling and reuse to reduce preconcentration costs associated with consumable materials and time used in procedures based on conventional solid-phase extraction cartridges.

\section{Conflicts of interest}

There are no conflicts to declare.

\section{Acknowledgements}

Authors are very grateful to the Brazilian agencies National Council for Scientific and Technological Development (CNPq 402281/2013-6, 401581/2016-0, 303137/2016-9), and São Paulo Research Foundation (FAPESP 2018/21489-1, 2013/24725-4 and 2015/2076-9) for financial support and fellowships (J. M. G. CNPq $141853 / 2015-8$, H. P. N. CNPq 141164/2015-8, and S. H. T. CNPq 305950/2016-9). We also thank Brazilian Nanotechnology National Laboratory - LNNano@CNPEM (Brazil) for the use of TEM/STEM facilities and the Laboratório de Materiais Magnéticos DFMT@IF-USP (Brazil) for the magnetic hysteresis measurement.

\section{Notes and references}

1 B. R. Scanlon, R. C. Reedy, P. Xu, M. Engle, J. P. Nicot, D. Yoxtheimer, Q. Yang and S. Ikonnikova, Sci. Total Environ., 2020, 717, 137085.

2 P. W. Mwaurah, S. Kumar, N. Kumar, A. K. Attkan, A. Panghal, V. K. Singh and M. K. Garg, Compr. Rev. Food Sci. Food Saf., 2020, 19, 3-20.

3 A. Shah, R. Fishwick, J. Wood, G. Leeke, S. Rigby and M. Greaves, Energy Environ. Sci., 2010, 3, 700-714.

4 A. L. Bolden, C. F. Kwiatkowski and T. Colborn, Environ. Sci. Technol., 2015, 49, 5261-5276.

5 S. Mitra and P. Roy, Res. J. Environ. Sci, 2011, 5, 394-398.

6 E. López, M. Schuhmacher and J. L. Domingo, Environ. Sci. Pollut. Res., 2008, 15, 278-288.

7 L. Maurice, F. López, S. Becerra, H. Jamhoury, K. Le Menach, M. H. Dévier, H. Budzinski, J. Prunier, G. JuteauMartineau, V. Ochoa-Herrera, D. Quiroga and E. Schreck, Sci. Total Environ., 2019, 690, 1203-1217.

8 C. L. Coonrod, Y. Ben Yin, T. Hanna, A. J. Atkinson, P. J. J. Alvarez, T. N. Tekavec, M. A. Reynolds and M. S. Wong, Water Res., 2020, 173, 115467.

9 P. R. F. da Costa, D. R. da Silva, C. A. Martínez-Huitle and S. Garcia-Segura, J. Electroanal. Chem., 2016, 763, 97-103.

10 A. Masih, A. S. Lall, A. Taneja and R. Singhvi, Atmos. Environ., 2016, 147, 55-66.

11 M. Dehghani, M. Fazlzadeh, A. Sorooshian, H. R. Tabatabaee, M. Miri, A. N. Baghani, M. Delikhoon, A. H. Mahvi and M. Rashidi, Ecotoxicol. Environ. Saf., 2018, 155, 133-143.

12 M. Pastor-Belda, P. Viñas, N. Campillo and M. HernándezCórdoba, Microchem. J., 2019, 145, 406-411.

13 M. Zhang, G. Huang, J. Huang, L. Zhong and W. Chen, RSC Adv., 2017, 7, 41862-41868.

14 E. Fernández, L. Vidal and A. Canals, J. Chromatogr. A, 2016, 1458, 18-24.

15 D. Orazbayeva, B. Kenessov, J. A. Koziel, D. Nassyrova and N. V. Lyabukhova, Chromatographia, 2017, 80, 1249-1256.

16 J. C. Flórez-Menéndez, M. L. Fernández-Sánchez, J. E. SánchezUría, E. Fernández-Martínez and A. Sanz-Medel, Anal. Chim. Acta, 2000, 415, 9-20.

17 M. Larriba, P. Navarro, J. García and F. Rodríguez, Energy Fuels, 2014, 28, 6666-6676. 
18 D. de A. Carvalho, R. M. de Oliveira, C. R. S. da Silva, P. T. Martinhon and S. A. da Silva, Rev. Ambient. Água, 2014, 9, 149-160.

19 M. A. Mottaleb, M. Z. Abedin and M. S. Islam, J. Environ. Sci., 2004, 16, 497-501.

20 Y. Liu and B. Shi, Chem. Eng. Technol., 2009, 32, 926-931.

21 E. Matisová and S. Škrabáková, J. Chromatogr. A, 1995, 707, 145-179.

22 S. Kim, N. K. Gupta, J. Bae and K. S. Kim, J. Hazard. Mater., 2020, 384, 121274.

23 A. A. Alqadami, M. Naushad, Z. A. Alothman and A. A. Ghfar, ACS Appl. Mater. Interfaces, 2017, 9, 36026-36037.

24 P. Tan, X.-Y. Xie, X.-Q. Liu, T. Pan, C. Gu, P.-F. Chen, J.-Y. Zhou, Y. Pan and L.-B. Sun, J. Hazard. Mater., 2017, 321, 344-352.

25 S. H. Kim, J. H. Park and C. Y. Lee, J. Porous Mater., 2013, 20, 1087-1093.

26 S. Štandeker, Z. Novak and Ž. Knez, J. Hazard. Mater., 2009, 165, 1114-1118.

27 H. P. Nogueira, S. H. Toma, A. T. Silveira, A. A. C. Carvalho, A. M. Fioroto and K. Araki, Microchem. J., 2019, 149, 104025.

28 S. Saire-Saire, E. C. M. Barbosa, D. Garcia, L. H. Andrade, S. Garcia-Segura, P. H. C. Camargo and H. Alarcon, RSC Adv., 2019, 9, 22116-22123.

29 L. A. Solovyov, O. V. Belousov, R. E. Dinnebier, A. N. Shmakov and S. D. Kirik, J. Phys. Chem. B, 2005, 109, 3233-3237.

30 S. H. Wu, C. Y. Mou and H. P. Lin, Chem. Soc. Rev., 2013, 42, 3862-3875.

31 Z. Li, J. C. Barnes, A. Bosoy, J. F. Stoddart and J. I. Zink, Chem. Soc. Rev., 2012, 41, 2590-2605.

32 F. Silencieux, M. Bouchoucha, O. Mercier, S. Turgeon, P. Chevallier, F. Kleitz and M. A. Fortin, Langmuir, 2015, 31, 13011-13021.

33 T. Kim, P. Chung and V. S. Lin, Chem. Mater., 2010, 22, 5093-5104.

34 J. Vega-Chacón, M. I. A. Arbeláez, J. H. Jorge, R. F. C. Marques and M. Jafelicci, Mater. Sci. Eng., C, 2017, 77, 366-373.

35 H. P. Nogueira, S. H. Toma, A. T. Silveira and K. Araki, J. Braz. Chem. Soc., 2020, 31, 2342-2350.
36 Q. H. Xia, K. X. Su, X. T. Ma, H. Q. Ge and H. B. Zhu, Mater. Lett., 2005, 59, 2110-2114.

37 H. Huang, C. Yang, H. Zhang and M. Liu, Microporous Mesoporous Mater., 2008, 111, 254-259.

38 T. Fagundes, A. W. L. Bachmann, H. S. O. Tomaz and C. A. Rodrigues, Quim. Nova, 2008, 31, 1305-1309.

39 S. Sharmasarkar, W. F. Jaynes and G. F. Vance, Water, Air, Soil Pollut., 2000, 119, 257-273.

40 R. G. Fischer and K. Ballschmiter, Fresenius' J. Anal. Chem., 1998, 360, 769-776.

41 H. Nourmoradi, M. Khiadani and M. Nikaeen, J. Chem., 2013, 589354, 10 pages, DOI: 10.1155/2013/589354.

42 M. I. Konggidinata, B. Chao, Q. Lian, R. Subramaniam, M. Zappi and D. D. Gang, J. Hazard. Mater., 2017, 336, 249-259.

43 Q. Lian, M. I. Konggidinata, Z. U. Ahmad, D. D. Gang, L. Yao, R. Subramaniam, E. Revellame, W. B. Holmes and M. Zappi, J. Hazard. Mater., 2019, 377, 381-390.

44 Z. Mamaghanifar, A. Heydarinasab, A. Ghadi and E. Binaeian, Water Conserv. Sci. Eng., 2020, 5, 1-13.

45 S.-H. Kim, J.-H. Park and C.-Y. Lee, J. Porous Mater., 2013, 20, 1087-1093.

46 D. G. da Silva, S. Hiroshi Toma, F. M. de Melo, L. V. C. Carvalho, A. Magalhães, E. Sabadini, A. D. dos Santos, K. Araki and H. E. Toma, J. Magn. Magn. Mater., 2016, 397, 28-32.

47 S. H. Toma, J. J. Santos, K. Araki and H. E. Toma, Anal. Chim. Acta, 2015, 855, 70-75.

48 K. Araki, M. Uchiyama, S. Toma, S. Rodrigues, A. Shimada, R. Loiola, H. Rodriguez, P. Oliveira, M. Luz, S. Rabbani, H. Toma and S. H. P. Farsky, Int. J. Nanomed., 2015, 4731.

49 A. Zuin, M. A. Novak, S. H. Toma, K. Araki and H. E. Toma, Carbon, 2014, 77, 600-606.

50 D. Garcia, G. Picasso, P. Hidalgo, H. E. M. Peres, R. Sun Kou and J. M. Gonçalves, Anal. Chem. Res., 2017, 12, 74-81.

51 J. Landers, G. Y. Gor and A. V. Neimark, Colloids Surf., A, 2013, 437, 3-32.

52 Y. Alsalka, F. Karabet and S. Hashem, Anal. Methods, 2010, 2, 1026-1035. 